DOI 10.37882/2223-2982.2021.03.15

\title{
РЕКОНСТРУКЦИЯ ПСИХОИСТОРИЧЕСКОГО ПОРТРЕТА Н.И. КОНДРАТЕНКО В КОНТЕКСТЕ ИСТОРИЧЕСКОЙ ПСИХОЛОГИИ
}

\section{RECONSTRUCTION OF PSYCHOHISTORICAL PORTRAIT OF KONDRATENKO N.I. IN THE CONTEXT OF HISTORICAL PSYCHOLOGY}

\section{K. Gusev}

Summary: In this article attempts are made to reconstruct the psychohistorical portrait of Kondratenko N.I., the Kuban's regional leader in 1997-2001, which included a wide range of personal qualities of the human individual.

The methodological basis of the research is an interdisciplinary approach the shuttle use of different psychological ideas and concepts from a historical retrospective of personality research. Based on the memoirs of contemporaries and personal texts of Kondratenko N.I., the main character traits of the politician are distinguished, and their psychohistorical analysis is made. In the context of the classical theory of Hippocrates and C.Galen, Kondratenko's temperament is attributed as "mixed" - between choleric and sanguine; according to Jung's classification, it is defined as "extroverted"; according to Kretschmer's approach, it is characterized as a "hypomanic type of cycloid temperament". Based on Erickson's theory, it is concluded that Kondratenko N.I. had a partial "identity crisis" in the early 1990s: with the retention of the individual's basic psychological traits and a significantly reconsidered ideological belief. It is emphasized that the data obtained enable to overcome the level of a single study of Kondratenko's personality and move on to the stage of a special one - the study of his social and political activity.

Keywords: historical psychology, psychohistory, Kondratenko N.I., temperaments, identity crisis, E. Kretschmer, C.G. Jung, E. Erikson.
Гусев Константин Дмитриевич Аспирант, ФГБОУ ВО «Кубанский государственный университет»

2. Краснодар

gusev-konstantin-2013@mail.ru

Аннотация: В статье осуществляется реконструкция психоисторического портрета Николая Игнатовича Кондратенко - регионального лидера Кубани в 1997-2001 гг., имевшего широкий спектр личностных качеств. Методологической основой исследования выступает междисциплинарный подход в контексте исторической психологии: челночное использование различных психологических идей и концепций в исторической ретроспективе исследования личности. На основе воспоминаний современников и персональных текстов Н.И. Кондратенко выделяются индивидуальные черты изучаемой личности, реализуется их психоисторический анализ. В рамках классической теории Гиппократа и К. Галена темперамент Н.И. Кондратенко атрибутируется как смешанный: между холериком и сангвиником; по классификации К.Г. Юнга, характер политика определяется в качестве экстравертного; согласно подходу э. Кречмера, индивид соотносится с гипоманиакальным типом циклоидного темперамента. Исходя из теории Э. Эриксона, делается вывод о частичном кризисе идентичности Н.И. Кондратенко в начале 1990-х гг. с сохранением базовых психологических черт и существенным пересмотром его идеологических взглядов. Подчёркивается, что полученные данные позволяют преодолеть уровень единичного исследования персоналии Н.И. Кондратенко и перейти к этапу особенного — к изучению его общественнополитической деятельности.

Ключевые слова: историческая психология, психоистория, Н.И. Кондратенко, темпераменты, кризис идентичности, Э. Кречмер, К.Г. Юнг, Э. Эриксон.

Для целостного оформления психоисторического портрета Н.И. Кондратенко релевантно применение концепции В.В. Ахтямова [1, с. 9-11], заключающегося в комбинационном использовании психологических подходов Гиппократа и К. Галена (классическая теория темпераментов), К.Г. Юнга (система психологических типов) [15], Э. Кречмера (типология тела и темпераментов) [5], Э. Эриксона (теория идентичности) [14] и Э. Фромма (социобиологический подход) [10]. Данный исследовательский вектор выглядит перспективным в свете развития исторической психологии - междисциплинарной области взаимодействия психологии и истории - для изучения психологического склада исторических эпох, внутренних изменений личности человека в социальном макровремени [13, с. 14-15]. Для осуществления ана- 
лиза принципиальным является эволюционный социобиологический историзм Э. Фромма: психологический тип человека определяет не только его биологическая предрасположенность, но и окружающая социальная действительность [10, с. 30-31]. Суммируя, конкретно сформулируем цель исследования - формирование психоисторического портрета Н.И. Кондратенко при использовании разнообразного набора психологических методов и подходов.

Воспоминания современников позволяют реконструировать широкую гамму личностных характеристик Н.И. Кондратенко: энергичный, трудолюбивый, порядочный, неравнодушный, эмоциональный, справедливый, яркий, убедительный, мудрый, красивый, профессиональный, стойкий, неповторимый, работоспособный, великодушный, уважительный, скромный, эрудированный, демократичный, патриотичный, самобытный, сострадательный, преисполненный юмора [7, с. 5-37]. Имеющееся разнообразие создаёт проблему чёткой атрибутации темперамента Н.И. Кондратенко. Используя классическую теорию Гиппократа и К. Галена, политолог С.Е. Шишкова-Шипунова определяет Н.И. Кондратенко как холерика: сильный, активный, независимый, горячий, взрывной, импульсивный и неуравновешенный [12, с. 173]. В то же время у Н.И. Кондратенко присутствовали ярко выраженные черты сангвиника: подвижный, открытый, позитивный, эмоционально-выразительный. В целом темперамент Н.И. Кондратенко возможно квалифицировать как смешанный: между сангвиником и холериком с преобладанием последнего.

Притягательность личности Н.И. Кондратенко отчасти объясняется иллюзорно-противоречивой конфигурацией наружных черт индивида: «Внешность его сочетала в себе и привычные признаки партийно-советской номенклатуры (высокий, крупный, „видный“ мужчина в костюме и галстуке) и забытые черты „вольного казака" - горячего, заводного, с живой, образной речью, природным юмором» [12, с. 166]. Н.И. Кондратенко был аккуратным, чистоплотным, безупречно одевавшимся; современники часто вспоминают о его красоте: о крупной фигуре, больших крепких руках, чёрных волосах, впоследствии полностью поседевших. Согласно теории Э. Кречмера, строение тела Н.И. Кондратенко соотносится с пограничным пикническо-атлетическим типом [5, с. 65]. Для пикников характерны плотная фигура с мягким широким лицом на короткой массивной шее, а также живот, расширяющийся к низу грудной клетки [5, с. 58]. Чертами атлетиков являются высокий рост с выступающими плечами, большой объём рук и существенная длина конечностей [5, с. 52-53]. Данное сочетание чаще всего предполагает циркулярный тип психологических особенностей конкретной персоналии.

Политическая карьера серьёзно не трансформиро- вала характер Н.И. Кондратенко: он сохранял простоту, открытость, не рвал связей со знакомыми. Показательна следующая характеристика: «Для нас, его земляков, Николай Игнатович - образец честности, порядочности, доброты, культуры поведения» [7, с. 42]. Многие отмечают, что гордятся знакомством и совместной работой с Н.И. Кондратенко [7, с. 75, 113]. Э. Кречмер выделяет два типа темпераментов: циклоидный и шизоидный [7, с. 170]. Для Н.И. Кондратенко свойственен циклоидный тип: общительный, человеколюбивый, добросердечный, весёлый, юмористичный, живой, легко адаптирующийся к окружающему.

При этом Н.И. Кондратенко оставался подвержен неконтролируемым эмоциям: мог сорваться, вспылить, накричать и обидеть [12, с. 172]. В его чертах присутствовали нотки истеризма: занимая различные посты, Н.И. Кондратенко часто угрожал собственной отставкой [12, с. 184]. Истерия - самая частая форма неврозов у экстравертов [15, с. 374]. Однако идеолог политической команды Н. Харченко отмечает, что Н.И. Кондратенко был отходчив: не таил обид и быстро их забывал [8, с. 125]. Г.В. Мухина, многолетняя помощница политика, подтверждает: «Он был патологически добрым, не мстительным человеком» [7, с. 6]. Перечисленные черты свидетельствуют о живом гипоманиакальном типе циклоидного темперамента Н.И. Кондратенко. Для такого человека характерны вспыльчивость, освежающий гнев, отходчивость: «Он не может держать язык за зубами... он не создан для того, чтобы таить недовольство... он ничего не оставляет после себя: скрытность, интриги, обидчивость ему чужды» [5, с. 173]. Так, для гипоманиакального темперамента свойственны бестактность и беспощадность, но в то же время нет холодной строгости, обидчивости, резкой враждебности и эксцентричности [5, с. 176].

Карьерный успех Н.И. Кондратенко отчасти объясняется такими чертами характера, как несгибаемость и работоспособность [7, с. 6]. Сын А.Н. Кондратенко вспоминает, что отец задавал «бешеный» темп, работал «на износ» [7, с. 22]. В зрелом возрасте Н.И. Кондратенко трудился по двенадцать часов в день практически без выходных, зачастую под давлением жёсткой критики. Политик отличался самоотдачей и дотошностью, вникал во все рабочие детали: от жизни доярки до хитросплетений экономической политики государства. В целом гипоманиакальные люди деятельны и предприимчивы, отчасти суетливы; это энергичные практики: они открыты, находчивы, смелы, порывисты, непосредственны, добросердечны, у них есть способность схватывать конъюнктуру [5, с. 180, 323]. Примечательно, что циклоидные люди не знают чувства утомления и сильного напряжения, получая удовольствие от работы [5, с. 176, 178].

Циклоиды не видят принципиального противоре- 
чия между «я» и общественной средой, что позволяет им сохранять сочувствие и сострадание к окружающим [5, с. 178]. Н.И. Кондратенко являлся сопереживающим и отзывчивом человеком, помогая всем, кто в этом действительно нуждался [7, с. 18]. Жена политика Л.П. Кондратенко подчёркивает: «...главным его качеством было неравнодушное отношение к людским проблемам» [7, с. 19]. Н.И. Кондратенко оказывал поддержку незнакомым людям в сложных жизненных ситуациях, даже когда это шло вразрез с законом: спасал жизни, находил врачей, решал жилищный вопрос. Так, циклоидные люди отличаются душевностью: откликаются на радости и горе, им свойственны теплота и добросердечие [5, с. 177]. Гипоманьяки этически отзывчивы, приятны в общении и способны на сопереживание [5, с. 178].

Согласно психологической классификации К.Г. Юнга, личность Н.И. Кондратенко целесообразно отнести к экстравертному типу, активно воспринимающему окружающий мир [15, с. 370]. Экстравертный человек быстро адаптируется к внешней среде, уделяет большое внимание окружающим его объектам, быстро, хотя не всегда точно определяет суть вещей [15, с. 562]. Такие люди уверены в себе, инициативны, доверительны, их психическая жизнь разыгрывается снаружи - во внешних объектах и взаимодействиях с ними [15, с. 562-563].

Современники выделяют широкий набор врождённых талантов Н.И. Кондратенко. Аналитический склад его мышления базировался на неординарных интеллектуальных способностях и пытливом уме. Сестра политика Т.И. Хоруженко вспоминает, что уже в детстве у Н.И. Кондратенко была фотографическая память: он много читал и почти всё запоминал с первого раза, любил учить и рассказывать стихи, пытался их писать [7, с. 2526]. Занимаясь политической деятельностью, он ничего не отмечал в блокноте, просто запоминая информацию [7, с. 36]. В целом обладатель гипоманиакального темперамента ни о чём не забывает, только если сам этого не захочет [5, с. 186].

Отмечается, что Н.И. Кондратенко мог стать учёным: ему предлагали поступать в аспирантуру [7, с. 35]. Сделавшись политиком, он часто удивлял современников познаниями, особенно в области сельскохозяйственных наук, по которым защитил кандидатскую и докторскую диссертации [3; 4]. Горизонт эрудиции Н.И. Кондратенко был весьма обширным: политик разбирался в литературе, живописи, истории, играл в шахматы, любил посещать музеи [7, с. 63]. В.Ф. Галушко подтверждает: «Он завораживал своими познаниями...» [7, с. 61]. Так, одарённые люди гипоманиакального темперамента резко выделяются над средним уровнем своими интеллектуальными способностями [5, с. 180]. Мышление как ключевая функция экстравертного типа позволяет им непосредственно соотносить свои действия с объективными условиями [15, с. 370-371].

Г.В. Мухина обратила внимание на интуицию политика - на «удивительное кондратенковское чутьё» [7, с. 5]. «Дар предвидения», образ неуслышанного пророка - непременные черты портрета Н.И. Кондратенко. Согласно К.Г. Юнгу, интуиция - это восприятие с помощью бессознательного, направленное в экстравертной установке на внешние объекты [15, с. 407]. Во многом благодаря развитой интуиции Н.И. Кондратенко охватывал всю полноту возможностей и принимал верные решения в проблемных ситуациях.

Наряду с другими качествами Н.И. Кондратенко современники часто выделяют его житейскую мудрость [7, с. 6]. Племянница Т. Новикова вспоминает, что в трудной ситуации обращалась к дяде и получала простой и в то же время полезный совет [7, с. 29]. Двоюродный брат политика В.А. Вряшник утверждает, что именно Николай Игнатович научил его «многим жизненным премудростям» [7, с. 30]. При этом Н.И. Кондратенко умел ненавязчиво развивать окружающих: учил работать в огороде, обустраивать дом, фотографировать, водить мотоцикл, помогал по учебе, рассказывал о достопримечательностях города [7, с. 30, 32]. Именно жизненная мудрость Н.И. Кондратенко помогала ему выстраивать крепкие личные связи с другими харизматичными лидерами и осуществлять созидательную политику в 1990-е гг.

Организаторский талант, ответственность, лидерские качества и высокий профессионализм являлись определяющими качествами для успешной карьеры Н.И. Кондратенко. Политик зарекомендовал себя как умелый и опытный хозяйственник, всегда действовал оперативно, не любил проволочек и опозданий. Так, многие циклоиды - живые организаторы крупного масштаба [5, с. 324]. Однако для Н.И. Кондратенко были свойственны доля спонтанности и отсутствие строгой последовательности. Быстрый темп жизни гипоманиакальных людей обуславливает их непостоянство; это практики, которые сначала знакомятся с реальными возможностями, а затем думают о принципах [5, с. 179].

Среди гипоманиакальных людей нередко встречаются выдающиеся ораторы [5, с. 180]. Н.И. Кондратенко являлся красноречивым мастером слова: «Говорил живо, страстно, эмоционально, то был настоящий природный дар, во многом определивший его судьбу народного лидера, трибуна» [12, с. 52]. О прирождённом ораторском таланте вспоминает Г.В. Мухина: «Так красиво и самобытно говорить, как Кондратенко, не каждому из политиков дано. Многие жители Кубани ждали его выступлений и верили каждому слову» [7, с. 7]. В.П. Громов характеризует Н.И. Кондратенко «непревзойдённым оратором» [7, с. 84-85]. При этом опубликованные речи Н.И. Кондратенко весьма объёмны: он говорил обо всём, не сдер- 
живал себя в выражениях, переходя границы словесных норм. Специфика необычного языка политика, богатого местными диалектизмами и поговорками, сформировалась в детстве: до школы Н.И. Кондратенко говорил на кубанской балачке, унаследованной от матери [7, с. 25, 33]. Л. Новикова вспоминает, что политик балакал и во взрослом возрасте [7, с. 27-28].

В целом для темперамента циклоида свойственна потребность высказаться: через взаимодействие с людьми он получает душевное движение и облегчение, такой человек захватывает всю аудиторию. Психомоторная сфера Н.И. Кондратенко соотносится с гипоманиакальным темпераментом: быстрые и обильные движения обеими руками, подвижная выразительная мимика лица. Гипоманьяки говорят быстро и много, то уклоняясь в сторону, то возвращаясь к сути дела [5, с. 186].

Часто обращают внимание на традиционный набор идей Н.И. Кондратенко («угроза сионизма», «цены на энергоресурсы»), которые регулярно повторял политик. С.Е. Шишкова-Шипунова вспоминает: «Поначалу речи его потрясли и заворожили многих, но со временем стало понятно, что говорит он, в общем, одно и то же...» [12, с. 52]. Н. Харченко считает, что Н.И. Кондратенко делал повторы сознательно исходя из принципа «капля камень точит» $[8$, с. 7]. Это ключевой недостаток гипоманиакальных темпераментов: их мышление работает экстенсивно, не проникает вглубь, охватывая верхний слой самых разнообразных сфер [5, с. 182].

Два уровня жизни Н.И. Кондратенко - общественный и домашний - значительно отличались друг от друга, причём первый полностью превалировал. Жена Н.И. Кондратенко подсчитала, что две трети их совместной жизни были отданы работе. Семейные узы являлись крайне важными для Н.И. Кондратенко: до конца своих дней он сохранял тесную связь с матерью, женой, сыновьями, сестрой, внуками. Именно личная жизнь оставалась для политика отдушиной, где он мог, даже работая физически, переключиться и отдохнуть от общественной деятельности. В семейном кругу Н.И. Кондратенко практически не использовал роль политика, сознательно ограждая близких от своей работы. Дефицит уделяемого внимания детям он компенсировал качеством общения: «Отец старался в редкие выходные навёрстывать упущенное» [7, с. 21]. Н.И. Кондратенко воспитывал сыновей в строгости, приучал их работать, готовил к службе в армии, привилегиями не баловал. Младший сын А.Н. Кондратенко вспоминает, что братья не испытывали исключительности, росли, «как нам казалось, в обычной семье» [7, с. 20-21]. Во многом Н.И. Кондратенко дублировал модель собственного «рабочего» воспитания, которое дала ему мать. Именно воспитательный фактор в совокупности с благоприятным социальным окружением Н.И. Кондратенко помог ослабить традиционные недостатки гипоманиакального характера: поверхностность, бестактность, переоценку самого себя.

Для целостного восприятия многогранной личности Н.И. Кондратенко уместно использование категории идентичности - тождественности человека самому себе $[14$, с. 12]. Согласно Э. Эриксону, это твёрдо усвоенный и принимаемый образ себя во всём богатстве отношений личности к окружающему миру, чувство адекватности и стабильного владения индивидом собственным «я» $[14$, с. 12]. Как правило, устойчивая идентичность, пройдя ряд кризисов, складывается к двадцати пяти годам. Однако «кризис идентичности» может произойти и у сформировавшейся личности при наступлении тяжёлых жизненных обстоятельств, в каких оказался Н.И. Кондратенко в 1991 г. Показательно, что тогда психологические черты политика практически не трансформировались: «...в сути своей человеческой он не изменился, не перелицевался ни в собственника, ни в капиталиста, а мог бы, ещё как мог!» [8, с. 267]. Обращается внимание на сохранение бескомпромиссности и принципиальной честности Н.И. Кондратенко [8, с. 267].

Положительными качествами политика остались дружелюбие и готовность прийти на выручку [7, с. 18]. В целом гипоманиакальные люди часто оказываются под влиянием среды, радуются новым людям и сразу сближаются с ними [5, с. 178]. Именно поэтому предательство друзей стало личным ударом для Н.И. Кондратенко в 1991 г., спровоцировавшим ситуацию «кризиса идентичности». В то же время Н.И. Кондратенко нельзя назвать компанейским человеком: он не любил шумных компаний, предпочитая отдавать свободное от работы время семье. Несмотря на экстравертный тип поведения в политической сфере, в обычной жизни Н.И. Кондратенко оставался «стеснительным и очень скромным человеком, не любил публичности» [7, с. 6-7]. Эту модель он пытался безуспешно перенести в политическую область: «Смотрите, чтобы меня было меньше в телевизоре и на страницах газет» [7, с. 7]. Нестяжательство осталось неизменной чертой политика с советских времен: он избегал привилегий, денежных состояний, жил в Краснодаре в обычной квартире [12, с. 179]. Отметим, что скромность проявлялась на протяжении всей жизни Н.И. Кондратенко и не была показной.

Н.И. Кондратенко не имел порока тщеславия: все попытки похвалы в свой адрес пресекал, льстецов и подхалимов не любил, полученные награды размещал на специальном пиджаке, который надел публично лишь один раз [7, с. 19, 73]. Самолюбие у Н.И. Кондратенко существовало, но носило скорее политический характер. С.Е.Шишкова-Шипунова объясняет этим как согласие политика идти на губернаторские выборы 1996 г., так и отказ баллотироваться на второй срок в 2000 г. [12, с. 194]. При этом Н.И. Кондратенко нельзя назвать карье- 
ристом: он не стремился к высоким постам как самоцели, «все атрибуты власти его не прельщали» [7, с. 22]. У циклоидов очень редко встречается сильное честолюбие, практические влечение к труду у них сильнее, нежели стремление к высоким идеалам [5, с. 179].

Н.И. Кондратенко всегда оставался связан с родной землёй, постоянно возвращаясь в станицу Пластуновскую. В.А. Вряшник вспоминает: «Любовь к земле, как и к своей малой родине - Динскому району, была у Николая какая-то особенная» [7, с. 30]. Политик считал, что мужчина должен уметь делать всё собственными руками: пахать, сеять, сажать, красить, штукатурить, готовить [7, с. 31, 42]. Уже будучи губернатором, он уезжал в станицу и работал на своём образцовом огороде, сохраняя хозяйство матери. Данное переключение играло для Н.И. Кондратенко восстановительную функцию: уединяясь в кругу семьи и домашних забот, он ненадолго переставал быть политиком.

Чувство юмора - неотъемлемая черта личности Н.И. Кондратенко, она характерна для циклоидных темпераментов [5, с. 177]. С.Е. Шишкова-Шипунова называет юмор политика специфическим, «грубовато-простонародным» $[12$, с. 176]. Л.П. Кондратенко подтверждает, что юмор мужа был «какой-то особый» [7, с. 10-11]. В обычной жизни Н.И. Кондратенко оставался человеком весёлым, улыбчивым, много шутил и часто смеялся. Среди гипоманьяков нередко встречаются юмористы [5, с. 324]. Т. Новикова вспоминает, что у Н.И. Кондратенко всегда был в запасе анекдот, который он «так классно рассказывал» [7, с. 27]. Весёлое настроение циклоидов помогает им ускорять психический темп активной практической деятельности. В целом описанный темперамент сочетает в себе солнечную весёлость и гневливое настроение, горячность, практичность и суетливость.

Однозначно классифицировать идеологические взгляды Н.И. Кондратенко после 1991 г. сложно [12, с. 132]. С одной стороны, он положительно отзывался о советском периоде истории, однако, будучи союзником КПРФ, сам в партию не вступал, призывая формировать широкий народно-патриотический фронт. С.Е.Шишкова-Шипунова парадоксально охарактеризовала позицию политика «мучительными метаниями между коммунистическим интернационализмом и великорусским национал-патриотизмом» [5, с. 135]. Это объясняется кризисом идеологических взглядов Н.И. Кондратенко после краха Советского Союза, попыткой эклектичного синтеза старых идей и реалий нового времени. Однако монолитность воззрений в 1990-е гг. перестала являться необходимым атрибутом политического лидера. Именно поэтому новая и неустойчивая система взглядов Н.И. Кондратенко не помешала ему в 1993 г. возобновить политическую карьеру и успешно строить её на протяжении дальнейших двадцати лет.

Таким образом, в условиях наложившихся друг на друга личностного и общественного кризисов Н.И. Кондратенко скорректировал собственную идентичность: оставив прежнюю модель поведения и конфигурацию психологических черт, он трансформировал набор своих идеологических взглядов. Данный кризис идентичности возможно охарактеризовать как частичный.

Подводя итоги, выделим ключевые штрихи психоисторического портрета Н.И. Кондратенко. Согласно теории Гиппократа и К. Галена, у политика был смешанный темперамент: между сангвиником и холериком с преобладанием последнего. Это обусловило его индивидуальную подвижность, позитивность, горячность, независимость и эмоциональную выразительность. По Э. Кречмеру, Н.И. Кондратенко присущ гипоманиакальный тип циклоидного темперамента с пограничным пикническо-атлетическим строением тела. Такому индивиду свойственны: повышенная активность, говорливость, общительность, работоспособность, вспыльчивость, отходчивость. В контексте психологической классификации К.Г. Юнга личность Н.И. Кондратенко соотносится с экстравертным темпераментом, благодаря которому индивид быстро адаптируется к окружающей среде и находится с ней в активной взаимосвязи. Исходя из теории Э. Эриксона, кризис идентичности Н.И. Кондратенко в начале 1990-х гг. возможно определить как частичный: политик смог сохранить базовый набор психологических черт, существенно трансформировав свои идеологические взгляды. В целом полученные данные снимают научную неприкосновенность с изучения персоналии Н.И. Кондратенко, помогают проанализировать его как отдельного человеческого индивида, что позволяет выйти на новый эвристический уровень исследования и начать конкретный анализ общественной и административной деятельности политика.

ЛИТЕРАТУРА

1. Ахтямов В.В. Психоисторические аспекты жизни и деятельности С.Ю. Витте и П.А. Столыпина: автореф. дис. ... канд. ист. наук. Омск, 2005.

2. Батько Кондрат: от сердца к сердцу / под ред. В.С. Ротова. Краснодар, 2000.

3. Кондратенко Н.И. Особенности формирования урожая сорто-подвойных комбинаций яблони в Прикубанской зоне садоводства в зависимости от уровня минерального питания: автореф. дис. ... канд. с.-х. наук. Краснодар, 1997. 
4. Кондратенко Н.И. Экологические аспекты создания промышленных насаждений яблони на Северо-Западном Кавказе: автореф. дис. ... д-ра с.-х. наук. Ставрополь, 2000.

5. Кречмер Э. Строение тела и характер. М., 2019.

6. Куда звал нас батько Кондрат. Майкоп, 2006.

7. Н.И. Кондратенко. След на земле // сост. Г.В. Мухина. Краснодар, 2015.

8. С любовью к Родине // сост. В.Г. Кондрашин, Ю.В. Ластовкин. Майкоп, 2003.

9. Слизовский Д.Е. Рецензия на статью К.Д. Гусева «Общественно-политическая деятельность Н.И. Кондратенко: историографический аспект» // Вопросы национальных и федеративных отношений. 2020. Т.10. Вып. 5. С.1398-1404.

10. Фромм Э. Анатомия человеческой деструктивности. М., 2020.

11. Шапкина Е.В. Харизматическое лидерство в политическом процессе: автореф. дис. . . . канд. полит. наук. Улан-Удэ, 2007.

12. Шишкова-Шипунова С.Е. Десять правителей Кубани. Краснодар, 2015.

13. Шкуратов В. Историческая психология. Ростов-на-Дону, 1994.

14. Эриксон Э. Идентичность: Юность и кризис. М., 1996.

15. Юнг К.Г. Психологические типы. Минск, 1998.

() Гусев Константин Дмитриевич (gusev-konstantin-2013@mail.ru).

Журнал «Современная наука: актуальные проблемы теории и практики»

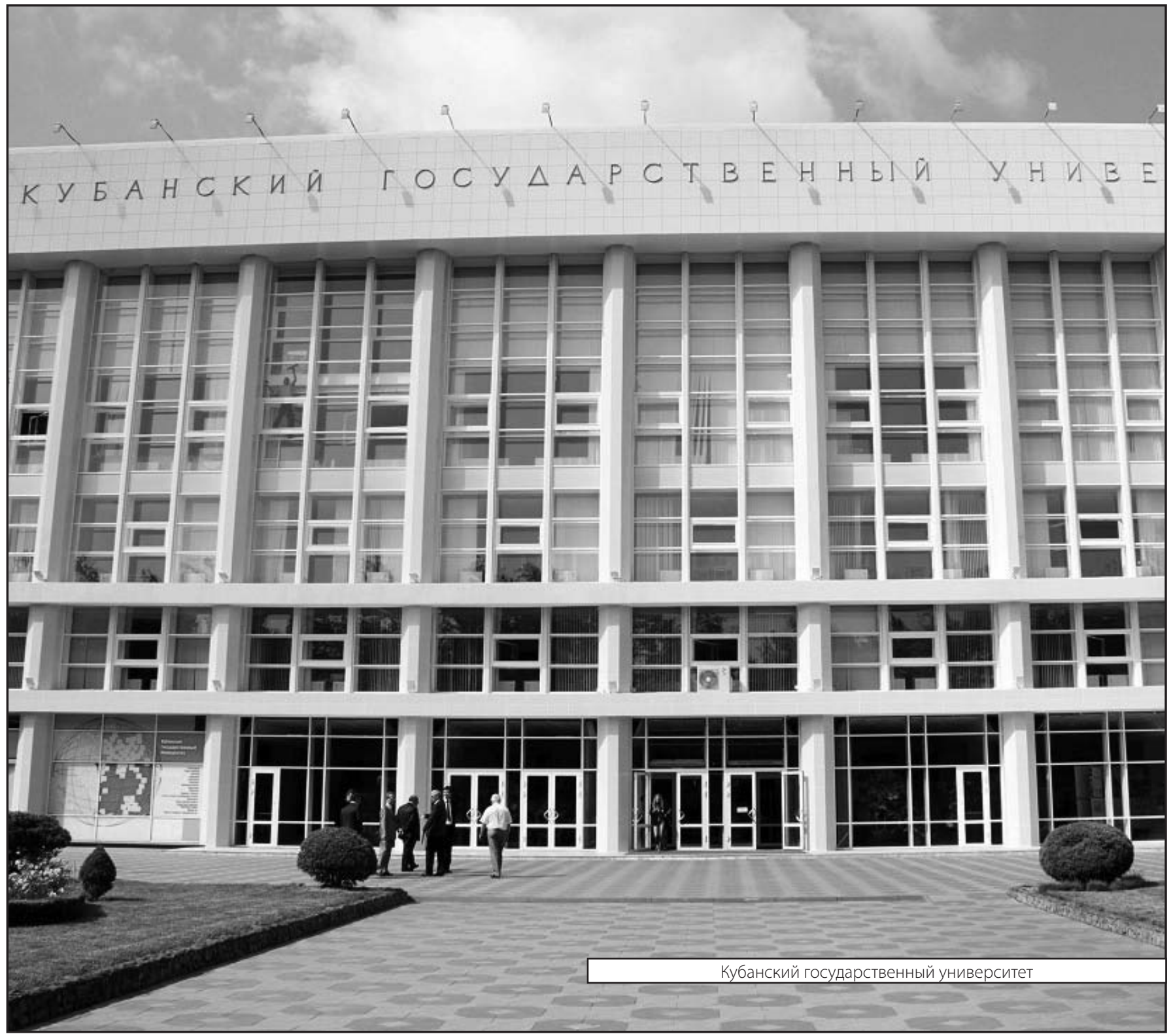

